УДК 347.1

О. Н. Захарова

Байкальский государственный университет, г. Иркутск, Российская Федерация

Т. Ю. Епифанцева

Байкальский государственный университет,

г. Иркутск, Российкая Федерация

\title{
К ВОПРОСУ О СПОСОБАХ РАСТОРЖЕНИЯ ДОГОВОРА
}

\begin{abstract}
АНнотАЦия. Статья посвящена вопросу о способах расторжения договора в свете последних изменений в гражданском законодательстве и разъяснений, данных по этой теме Пленумом Высшего Арбитражного Суда Российской Федерации. Представлена авторская позиция по систематизации способов расторжения гражданско-правового договора: по соглашению сторон и по инициативе одной из сторон. Последовательно рассмотрены вопросы о способах, порядке и основаниях расторжения гражданско-правовых договоров. Основное внимание в статье уделено анализу особенностей реализации права на односторонний отказ от договора (отказ от исполнения договора). Акцентируется внимание на том, что такой односторонний отказ от договора может быть как мотивированным (т.е. право на отказ может быть вызвано неисполнением договорного обязательства другой стороной), так и немотивированным (т. е. право на отказ от договора не связано с какими-либо нарушениями или специальными основаниями).

КЛЮЧЕВЫЕ СЛОВА. Способы расторжения договора; расторжение по соглашению; расторжение в судебном порядке; односторонний отказ от договора; односторонний отказ от исполнения договора; мотивированный отказ; немотивированный отказ от договора.
\end{abstract}

ИНФОРМАЦИЯ О СТАТЬЕ. Дата Поступления 15 июня 2016 г.; дата принятия к печати 1 июля 2016 г.; дата онлайн-размещения 30 сентября 2016 г.

O. N. Zakharova Baikal State University, Irkutsk, Russian Federation

T. Yu. Epifantseva Baikal State University, Irkutsk, Russian Federation

\section{REVISITING THE WAYS OF TERMINATING CONTRACTS}

ABSTRACT. The article is devoted to the issue of ways of terminating contracts in terms of the recent changes in the civil legislation and in explanations given in on this topic by the Plenum of Supreme Arbitrary Court of the Russian Federation. It presents the author's position on systemizing the ways of terminating civil-legal contracts: by agreement of the parties and at the initiative of either party. It gives a consequent consideration of the issues of the ways, order and ground of terminating civil-legal contracts. The article pays its main attention to analyzing the features of implementing the rights for one-side renunciation of the contract (renunciation of contract implementation). It emphasizes the fact that such a one-side contract renunciation can be both motivated (that is, the right for renunciation can be caused by breach of contract by the other party) and non-motivated (that is, the right for renunciation is not connected with certain breaches or specific grounds).

KEYWORDS. Ways of contract termination; renunciation by agreement; renunciation by juridical process; one-side contract renunciation; one-side renunciation of contract implementation; motivated renunciation; non-motivated contract renunciation.

ARTICLE INFO. Received June 15, 2016; accepted July 1, 2016; available online September $30,2016$.

\section{Baikal Research Journal}


Способы расторжения гражданско-правового договора закреплены ст. 450-450.1

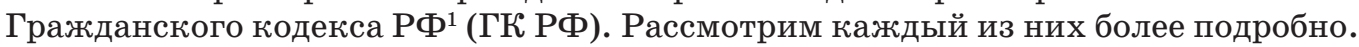

В соответствии с п. 1 ст. 450 ГК РФ расторжение договора возможно по соглашению сторон, если иное не предусмотрено ГК РФ, иными законами или договором. Данное положение полностью соответствует основополагающему принципу принципу свободы договора, которым, в частности, предусмотрена как возможность свободного вступления в договорные отношения, так и свободное волеизъявление на их прекращение путем расторжения по обоюдному согласию.

Многосторонний договор, участниками которого являются только субъекты предпринимательской деятельности, может быть расторгнут как по соглашению всех, так и большинства участников такого договора, если иное не предусмотрено законом (абз. 2 п. 1 ст. 450 ГК РФ). Однако для реализации такого способа расторжения многостороннего договора необходимо прямо предусмотреть этот порядок в самом многостороннем договоре. Следует отметить, что данная норма, скорее всего, применима не ко всем многосторонним договорам [1, с. 48; 2, с. 147-156].

Таким образом, указанный способ расторжения договора (по соглашению сторон) реализуется во внесудебном порядке.

Второй способ расторжения договора - по инициативе одной из сторон. Именно этот способ расторжения договора претерпел значительные изменения в законодательном регулировании, а также до сих пор остается сложным и дискуссионным как в теории, так и на практике. М. И. Брагинский и В. В. Витрянский отмечают, что особенностью расторжения договора в одностороннем порядке является отсутствие согласия со стороны контрагента, а если бы оно было, то речь пошла бы об ином основании - по соглашению [3, с. 434].

Расторжение договора по инициативе одной из сторон предполагает его расторжение как в судебном, так и во внесудебном порядке, как по основаниям, предусмотренным законом, так и договором. При этом под внесудебным порядком следует понимать расторжение договора без необходимости обращения в суд с иском о расторжении $[4$, c. 60$]$. Для начала обратимся к вопросу о расторжении договора по инициативе одной из сторон в судебном порядке.

В соответствии с п. 2 ст. 450 ГК РФ договор может быть расторгнут по требованию одной из сторон по решению суда в случае существенного нарушения договора другой стороной, а также в иных случаях, предусмотренных законом или договором. Из этого правила можно сделать следующие выводы.

Во-первых, по решению суда может быть расторгнут любой гражданско-правовой договор в силу существенного нарушения его другой стороной. При этом бремя доказывания существенности нарушения договорных условий лежит на стороне, обратившейся в суд с требованием о расторжении [5, с. 134]. Само понятие существенного нарушения договора предполагает наличие такого ущерба, что сторона в значительной степени лишается того, на что была вправе рассчитывать при заключении договора (абз. 2 п. 2 ст. 450 ГК РФ). Данная категория является оценочной и, в конечном счете, определяется судом.

Во-вторых, по решению суда по инициативе одной из сторон договор может быть расторгнут в случаях, предусмотренных законом. Так, например, такие законодательные установки прямо предусмотрены ст. 619, 620 ГК РФ (досрочное расторжение договора аренды по инициативе сторон); п. 2 ст. 687 ГК РФ (расторжение договора найма жилого помещения по требованию наймодателя). Частный случай расторжения договора по инициативе одной стороны в судебном порядке предусмо-

${ }^{1}$ Гражданский кодекс Российской Федерации (часть первая) : федер. закон от 30 нояб.1994 г. № 51-ФЗ (ред. от 23 мая 2016 г.) // Российская газета. 1994. 8 дек.

\section{Baikal Research Journal}

электронный научный журнал Байкальского государственного университета 
трен ст. 451 ГК РФ (расторжение договора в связи с существенным изменением обстоятельств). Интересно, что только в этих нормах ГК РФ законодатель ссылается на возможность расторжения именно в судебном порядке. Однако сама по себе возможность расторжения договора по инициативе одной стороны, без специального указания на судебный порядок, предусмотрена во многих нормах ГК РФ (см. абз. 2 п. 1 ст. 460 , п. 1 ст. 599 , п. 1 ст. 693 , ст. 698 , п. 6 ст. 709 и др.). Думается, что и в этих, перечисленных нормах ГК РФ, подразумевается возможность расторжения договора в судебном порядке.

В-третьих, в силу буквального понимания п. 2 ст. 450 ГК РФ по решению суда по инициативе одной из сторон договор может быть расторгнут в предусмотренных им случаях. В соответствии с п. 2 ст. 1 и ст. 421 ГК РФ граждане и юридические лица свободны в установлении своих прав и обязанностей на основе договора и в определении любых не противоречащих законодательству условий договора. Таким образом, стороны свободны в установлении условий договора относительно отдельных случаев расторжения договора в судебном порядке. Представляется, что предусмотренные договором случаи расторжения договора в судебном порядке могут быть как существенными, так и не существенными с точки зрения нарушения договора. Так, например, стороны по договору аренды могут предусмотреть условие, по которому арендодатель вправе требовать расторжения договора в судебном порядке, даже в случае однократного невнесения арендной платы. Однако во всех случаях контрагентам необходимо помнить, что недопустимо злоупотребление своими правами в условиях свободы определения договорных условий в нарушение охраняемых законом интересов третьих лиц или публичных интересов ${ }^{2}$.

Ранее нами уже было отмечено, что расторжение договора по инициативе одной из сторон предполагает его расторжение как в судебном, так и во внесудебном порядке. Остановимся теперь подробнее на внесудебном порядке расторжения договора, под которым мы подразумеваем односторонний отказ от договора (отказ от исполнения договора).

Односторонний отказ от договора как способ расторжения договора предусмотрен п. 1 ст. 450.1 ГК РФ. Согласно указанной норме односторонний отказ от договора может быть предусмотрен законом, иным правовым актом или договором. Из этого правила можно сделать следующие выводы.

Во-первых, односторонний отказ от договора может быть предусмотрен законами или иными правовыми актами. Действительно, в ГК РФ практически во всех видах договорных обязательств предусмотрено право стороны на односторонний отказ от договора или его исполнения. Например, в рамках обязательства купли-продажи такое право предусмотрено ст. $475,480,489,503$ и др.; в рамках арендных обязательств - ст. 610,627 ; по договору безвозмездного пользования право на односторонний отказ от договора - ст. 699 ; в рамках договора подряда - ст. 715,717 ; в рамках других обязательств - ст. 782, 977, 1002, 1010, 1024, 1037 и др. Кроме того, специальным случаем одностороннего отказа является п. 3 ст. 450.1 ГК РФ, предусматривающий право стороны отказаться от договора при отсутствии у другой стороны лицензии на осуществление деятельности или членства в саморегулируемой организации, необходимых для исполнения обязательства.

При анализе оснований одностороннего отказа от договора следует, что он может быть как мотивированным, так и немотивированным. Мотивированный отказ от договора представляет собой оперативную санкцию в ответ на нарушение договора другой стороной $[6$, с. $27 ; 7$, с. 66$]$. Так, например, в соответствии со ст. 475 ГК РФ

${ }^{2}$ О свободе договора и ее пределах : постановление Пленума ВАС РФ от 14 марта 2014 г. № 16. П. 8 // Вестник Высшего Арбитражного Суда РФ. 2014. № 5.

\section{Baikal Research Journal}

электронный научный журнал Байкальского государственного университета 
покупатель вправе отказаться от договора купли-продажи в случае передачи ему товара с существенными недостатками; в соответствии со ст. 523 ГК РФ односторонний отказ от договора поставки возможен в случае существенного нарушения договора одной из сторон (неоднократная просрочка поставки, невыборка товара); ст. 717 ГК РФ предусматривает право заказчика отказаться от договора подряда в случае, если в разумный срок подрядчиком не будут устранены недостатки в работе. Так или иначе, во всех случаях мотивированного отказа от договора мы сталкиваемся с недобросовестностью контрагента [8, с. 77].

Немотивированный отказ от договора, т.е. отказ во всяком случае и в любое время, можно рассматривать как некую привилегию [9, с. 36; 10, с. 91-97]. На самом деле в силу особой юридической природы договора отказ от него может быть совершенно не связан с его нарушением. Немотивированный отказ от договора предусмотрен ст. 610, 699, 717, 782 и др.

Во-вторых, односторонний отказ от договора может быть предусмотрен самим договором. В этой связи необходимо помнить положения ст. 310 ГК РФ, согласно которой согласование в договоре права на односторонний отказ возможно только в случае, когда такой договор заключается между субъектами предпринимательской деятельности, а также в случае, когда право на односторонний отказ предоставлено договором стороне, которая не осуществляет предпринимательскую деятельность. Целью, которую преследует законодатель в данном случае, является защита более слабой стороны по договору. Однако далеко не во всех случаях ст. 310 ГК РФ применима в так называемых потребительских договорах [11, с. 25].

Представляется, что односторонний отказ от договора, предусмотренный самим договором, также может быть как мотивированным, так и немотивированным. В связи с этим трудно согласиться с мнением, согласно которому беспричинное, досрочное расторжение обязательств путем только лишь заблаговременного уведомления другой стороны, противоречит принципам обеспечения стабильности гражданского оборота [12, с.93].

Важным для всех способов расторжения договоров является правильное установление момента и порядка расторжения договора. В случае расторжения договора по соглашению сторон, договор считается расторгнутым с момента достижения соглашения сторон о его расторжении. Форма соглашение о расторжении договора подчиняется правилам форме заключения договора. В случае расторжения договора по инициативе одной стороны в судебном порядке, договор считается расторгнутым с момента, определенного в решении суда. И, наконец, в случае реализации права на односторонний отказ от договора, он считается расторгнутым с момента получения уведомления другой стороной об отказе от договора, если иное не предусмотрено законом или договором. Так, уведомление об отказе от договора в одностороннем порядке заказчику по договору возмездного оказания услуг следует отправлять заблаговременно, так как исполнитель не может предполагать о прекращении договорных отношений до тех пор, пока не получит уведомления [13, с. 12; 14, с. 17$]$.

Способ расторжения договора влияет также и на порядок внесения записи о расторжении зарегистрированного договора. Так, в соответствии с п. 11 Постановления Пленума ВАС РФ от 6 июня 2014 г. № $35^{3}$, если договор был расторгнут по решению суда, то запись вносится на основании вступившего в силу судебного акта. Если договор был расторгнут путем немотивированного отказа от его исполнения, то запись вносится по заявлению стороны, воспользовавшейся таким правом с представлением в регистрирующий орган доказательства уведомления другой стороны об отказе.

${ }^{3}$ О последствиях расторжения договора : постановление Пленума ВАС РФ от 6 июня 2014 г. № 35 // Вестник Высшего Арбитражного Суда РФ. 2014. № 8.

\section{Baikal Research Journal}

электронный научный журнал Байкальского государственного университета 
И, наконец, если односторонний отказ от договора был связан с нарушением его другой стороной, то запись вносится по заявлению обеих сторон, а в случае отказа стороны, сторона, отказавшаяся от договора, вправе обратиться в суд с иском $\kappa$ другой стороне о признании договора прекратившимся. Решение суда об удовлетворении указанного иска служит основанием для внесения записи в реестр. Данные правила касаются только договоров, которые подлежат государственной регистрации в соответствии с требованием законодательства. В связи с этим считаем ошибочной точку зрения М. А. Егоровой, которая указывает на то, что в фидуциарных обязательствах, таких как поручение, комиссия, агентирование, а также в бессрочной аренде может возникнуть необходимость обращения в регистрирующий орган [15, с. 36].

Подводя итог нашему исследованию, обозначим следующие выводы.

Во-первых, в действующем законодательстве предусмотрены два способа расторжения договора: по соглашению сторон и по инициативе одной стороны договора.

Во-вторых, расторжение договора по соглашению сторон реализуется всегда во внесудебном порядке, и договор считается расторгнутым с момента достижения сторонами соглашения о его расторжении в установленной законом форме. Данный способ расторжения договора в полной мере соответствует принципу свободы договора.

В-третьих, расторжение договора по инициативе одной из сторон предполагает его расторжение как в судебном, так и во внесудебном порядке, как по основаниям, предусмотренным законом, так и договором. При этом расторжение договора по инициативе одной из сторон во внесудебном порядке представляет собой односторонний отказ от договора (или исполнения договора). Такой односторонний отказ от договора может быть как мотивированным, т. е. право на отказ может быть вызвано неисполнением договорного обязательства (как предусмотренные законом, так и договором) другой стороной, так и немотивированным, т. е. право на отказ от договора не связано с какими-либо нарушениями или специальными основаниями.

В случае расторжения договора по инициативе одной стороны в судебном порядке договор считается расторгнутым с момента, определенного в решении суда. А в случае реализации права на односторонний отказ от договора, он считается расторгнутым с момента получения уведомления другой стороной об отказе от договора, если иное не предусмотрено законом или договором.

\section{Список использованной литературы}

1. Кулаков В. В. Межкредиторское соглашение как новый вид гражданско-правового договора / В. В. Кулаков // Законы России: опыт, анализ, практика. -2016 . - № 2. C. $45-50$.

2. Качкин Д. В.Соглашение о государственно-частном партнерстве как гражданско-правовой договор / Д. В. Качкин, Р. Р. Репин // Закон. - 2015. — № 10. - С. 147-156.

3. Брагинский М. И. Договорное право. Книга первая: Общие положения / М. И. Брагинский, В. В. Витрянский. - Изд. 5-е, доп., стер. - М. : Статут, 2002. - 848 с.

4. Демкина А. В. Порядок и пределы реализации права на отказ от договора или от осуществления прав по договору: новые правила ГК РФ / А. В. Демкина // Имущественные отношения в Российской Федерации. - 2015. - № 11. - С. 57-65.

5. Захарова О. Н. Договор лизинга с правом выкупа: проблемы теории и практики / О. Н. Захарова // Известия Иркутской государственной экономической академии. - 2012. № 4 (84). - C. 132-136.

6. Дихтяр А. И. Банкротство: условия действительности одностороннего отказа арбитражного управляющего от исполнения договоров должника / А. И. Дихтяр // Арбитражный и гражданский процесс. - 2001. - № 3. - С. 23-29.

7. Хохлов В. А. Юридически значимые заверения в гражданском праве России / В. А. Хохлов // Журнал российского права. - 2016. - № 2. - С. 63-71.

8. Дроздова Т. Ю. Добросовестность в российском гражданском праве / Т. Ю. Дроздова. - Иркутск : Изд-во БГУЭП, 2006. - 152 с.

\section{Baikal Research Journal}

электронный научный журнал Байкальского государственного университета 
9. Егорова М. А. Односторонний отказ от исполнения гражданско-правового договора / М. А. Егорова. - 2 изд., перераб. и доп. - М. : Статут, 2010. - 528 с.

10. Усачева Е. А. Договорное определение порядка и последствий одностороннего отказа от договора возмездного оказания услуг: новеллы законодательства и судебной практики / Е. А. Усачева // Вестник Арбитражного суда Московского округа. — 2015. — № 3. - С. 91-97.

11. Ефимова Л. Г. Общие условия договора о выдаче и использовании банковской карты / Л. Г. Ефимова // Законы России: опыт, анализ, практика. - 2016. - № 2. - С. 23-29.

12. Свириденко О. М. О некоторых процессуальных проблемах, связанных с отказом арендатора от договора аренды / О. М. Свириденко // Журнал российского права. — 2015. № 12.-С. 90-94.

13. Бычков А. Плата за отказ от договора услуг / А. Бычков // ЭЖЖ-Юрист. - 2015. № 40. - C. 12-15.

14. Михеева И. А. Правовые особенности расторжения договора банковского счета, в рамках которого открыто несколько банковских счетов / И. А. Михеева // Банковское право. 2016. 一 № 1. - C. 14-20.

15. Егорова М. А. Правовые последствия изменения и расторжения договора / М. А. Егорова // Гражданское право. - 2016. — № 1. - С. 35-39.

\section{References}

1. Kulakov V. V. Inter-creditor agreement as a new kind of civil contract. Zakony Rossii: opyt, analiz, praktika = Law of Russia: Experience, Analysis, Practice, 2016, no. 2, pp. 45-50. (In Russian).

2. Kachkin D. V., Repin R. R. The public-private partnership agreement as a civil contract. Zakon =Law, 2015, no. 10, pp. 147-156. (In Russian).

3. Braginsky M. I., Vitryansky V. V. Dogovornoe parvo. Kniga pervaya: Obshchie polozheniya [Contractual Law. Book 1. General Provisions]. Moscow, Statut Publ., 2002. 848 p.

4. Demkina A. V. Concept of unilateral refusal to execute a contract or rights under the contract: new rules of the Civil Code. Imushchestvennye otnosheniya $v$ Rossiiskoi Federatsii $=$ Property Relations in the Russian Federation, 2015, no. 11, pp. 57-65. (In Russian).

5. Zakharova O. N. Lease agreement with the right of redemption: theoretical and practical issues. Izvestiya Irkutskoi gosudarstvennoi ekonomicheskoi akademii = Bulletin of Irkutsk State Economics Academy, 2012, no. 4 (84), pp. 132-136. (In Russian).

6. Dikhtyar A. I. Bankruptcy: validity conditions for one-side renunciation of executing debtors' contracts by the insolvency practitioner. Arbitrazhnyy $i$ grazhdanskiy protsess $=$ Arbitration and Civil Proceedings, 2001, no. 3, pp. 23-29. (In Russian).

7. KhokhlovV. A. Juristically significant representations in Russia's Civil Law. Zhurnal rossiyskogo prava = Journal of Russian Law, 2016, no. 2, pp. 63-71. (In Russian).

8. Drozdova T. Yu. Dobrosovestnost' $v$ rossiiskom grazhdanskom prave [Fair practice in Russian Civil Law]. Irkutsk, Baikal State University of Economics and Law Publ., 2006. 152 p.

9. Egorova M. A. Odnostoronnii otkaz ot ispolneniya grazhdansko-pravovogo dogovora [Oneside renunciation of executing a civil-legal contract]. $2^{\text {nd }}$ ed. Moscow, Statut Publ., 2010. 528 p.

10. Usacheva E. A. Contractual definition of the order and consequences of one-side renunciation of commutative service provision contract: novels of legislation and court practice. Vestnik Arbitrazhnogo suda Moskovskogo okruga = Bulletin of Arbitrary Court of Moscow District, 2015, no. 3, pp. 91-97. (In Russian).

11. Efimova L. G. General contract conditions on issuing and using a bank card. Zakony Rossii: opyt, analiz, praktika = Law of Russia: Experience, Analysis, Practice, 2016, no. 2, pp. 23-29. (In Russian).

12. Sviridenko O. M. Some procedural problems related to denunciating the tenant with regard to lease agreement. Zhurnal rossiyskogo prava = Journal of Russian Law, 2015, no. 12, pp. 90-94. (In Russian).

13. Bychkov A. Payment for denunciating service contracts. EJ-Jurist, 2015, no. 40, pp. 12-15.(In Russian).

14. Mikheyeva I. A. Legal features of terminating contracts of bank accounts which opened several bank accounts. Bankovskoe pravo = Banking Law, 2016, no. 1, pp. 14-20.(In Russian).

15. Egorova M. A. Legal consequences of amending and terminating a contract. Grazhdanskoe parvo $=$ Civil Law, 2016, no. 1, pp. 35-39. (In Russian).

\section{Baikal Research Journal}




\section{Информация об авторах}

Захарова Ольга Николаевна - кандидат юридических наук, доцент, кафедра теории государства и права и социально-правовых дисциплин, Юридический институт, Байкальский государственный университет, 664003, г. Иркутск, ул. Ленина, 11, e-mail: zaharovaon1976@mail.ru.

Епифанцева Татьяна Юрьевна - кандидат юридических наук, доцент, кафедра гражданского права и процесса, Юридический институт, Байкальский государственный университет, 664003, г. Иркутск, ул. Ленина, 11, e-mail: tanu@rambler.ru.

\section{Authors}

Olga N. Zakharova - PhD in Law, Associate Professor, Chair of Theory of State and Law and Socio-Legal Disciplines, Juridical Institute, Baikal State University, 11 Lenin St., 664003, Irkutsk, Russian Federation; e-mail: zaharovaon1976@mail.ru.

Tatyana Yu. Epifantseva - PhD in Law, Associate Professor, Chair of Civil Law and Procedure, Juridical Institute, Baikal State University, 11 Lenin St., 664003, Irkutsk, Russian Federation; e-mail: tanu@rambler.ru.

\section{Библиографическое описание статьи}

Захарова О. Н. К вопросу о способах расторжения договора / О. Н. Захарова, Т. Ю. Епифанцева // Baikal Research Journal. - 2016. - T. 7, № 5. - DOI : 10.17150/2411$\underline{6262.2016 .7(5) .16 .}$

\section{Reference to article}

Zakharova O. N., Epifantseva T. Yu. Revisiting the ways of terminating contracts. Baikal Research Journal, 2016, vol. 7, no. 5. DOI : 10.17150/2411-6262.2016.7(5).16. (In Russian).

\section{Baikal Research Journal}

